\title{
Foot-and-Mouth Disease Entrance Assessment Model Through Air Passenger Violations
}

\author{
Xiao-Wei Lin, ${ }^{1}$ Chin-Tsang Chiang, ${ }^{1}$ Tai-Hwa Shih, ${ }^{2}$ Yan-Nian Jiang, \\ and Chin-Cheng Chou ${ }^{4,5 *}$
}

This article aims to construct a risk model for the prediction of foot-and-mouth disease (FMD) entrance caused by passengers who illegally carry meat products of cloven-hoofed animals through international airports into a country. The risk that meat contaminated with the FMD virus is formulated as the probabilities of FMD factor events (the prevalence of FMD), the commodity factor event (the transportation, storage, and distribution (TSD) factor event), and the passenger event. Data used for analysis were records of illegal meat product carriers from areas A and B intercepted at an international airport in Taiwan. A risk model was proposed to simulate the probability distributions in disease prevalence, probability of FMD virus existing in the meat products after meat processing, and estimation of survival of virus and time period for TSD. The probability of the passenger event was hypothesized with the odds of intercepted passengers and estimated via logistic regression. The results showed that the odds of passengers being intercepted by beagles were higher than those intercepted by Customs. By conducting Monte Carlo simulations, the probability of FMD virus risk caused by FMD factors from area A was 149 times lower than that from area B. The probability of FMD virus risk caused by the passenger event from area A was four times lower than the corresponding probability from area $\mathrm{B}$. The model provides a contribution to FMD prevention and can be a reference for developing models of other diseases.

KEY WORDS: Air passenger; animal products; foot-and-mouth disease; logistic regression

${ }^{1}$ Department of Mathematics, National Taiwan University, No. 1, Section 4, Roosevelt Road, Taipei 106, Taiwan.

2 Hsinchu Branch, Bureau of Animal and Plant Health Inspection and Quarantine, No. 25, Harng Chin North Road, Taiwan Taoyuan International Airport, Taoyuan 337, Taiwan.

${ }^{3}$ Department of Animal Science and Technology, National Taiwan University, No. 50, Lane 155, Keelung Road, Section 3, Taipei 106, Taiwan.

${ }^{4}$ Department of Veterinary Medicine, National Taiwan University, No. 1, Section 4, Roosevelt Road, Taipei 106, Taiwan.

5 Center for Zoonoses Research, College of Bio-Resources and Agriculture, National Taiwan University, No. 1, Section 4, Roosevelt Road, Taipei 106, Taiwan.

* Address correspondence to Chin-Cheng Chou, Department of Veterinary Medicine, National Taiwan University, No. 1, Section 4, Roosevelt Road, Taipei 106, Taiwan; tel: +886-2-23630495; fax: +886-2-2363-0495; chouchin@ntu.edu.tw.

\section{INTRODUCTION}

Worldwide distribution of animals and their products through rapid international transportation has diminished the effect of natural geographic barriers on exotic animal diseases. ${ }^{(1)}$ The actual frequency of violations of animal product quarantine regulations by travelers at an international airport in Taiwan was significantly higher than the frequency of interceptions due to the low sensitivity of the detection system. ${ }^{(2)}$ In 1997, a policy for better baggage checking by sniffer dogs and X-ray scanners was commenced in New Zealand and the quantity in illegal meat imports was estimated to have reduced by more than $80 \%$ in $2000 .{ }^{(3)}$ International passengers who illegally carry animal products thus play an important role in risk evaluation. ${ }^{(4)}$ 
Foot-and-mouth disease (FMD) is a highly contagious viral disease of cloven-hoofed animals and is commonly associated with the movement of animals or the shipment of food contaminated with the FMD virus. ${ }^{(5,6)}$ A proportion of the FMD virus may still survive after meat processing steps such as chilling, curing, drying, and steaming. ${ }^{(7,8)}$ The introduction of the FMD virus into a foreign country via meat products can be assessed by the risk assessment study based on factor events of prevalence of FMD in the country of origin, the commodity factor event, and the transportation, storage, and distribution (TSD) factor event. The FMD infection risk posed on the livestock population of Great Britain from illegal importation of meat was estimated through the development of a quantitative risk assessment model, and $47 \%$ of risk came from imports originating in the Near and Middle East region. ${ }^{(9)}$ Bone-in and dried deboned products pose the most concerns.

Taiwan had regained recognition of the FMDfree status with vaccination by the World Organization for Animal Health (OIE) in 2003. Attention must therefore then be drawn to the risk of FMD entrance from carrier animals and related products that are transported intentionally or unintentionally by people. ${ }^{(3,10)}$ The aim of this study was thus to design a risk estimation model to predict the risk of FMD entrance caused by passengers who illegally carry meat products of cloven-hoofed animals through an international airport into Taiwan. The quantitative risk assessment model developed and the simulation results will provide useful information for decisionmakers to select effective and efficient policies for a better level of protection to prevent the entry of exotic pathogens.

\section{MATERIALS AND METHODS}

The probability for the risk of FMDcontaminated meat products to enter an international airport is conditional based on different areas of origin of the arriving passengers per year. The probability function in this study in one specific area is formulated as:

$$
P(\text { area })=P\left(N_{1} \times N_{2} \times N_{3} \times N_{4}\right),
$$

where $N_{1}$ is the prevalence of FMD, $N_{2}$ is the commodity factor event (the contaminating virus in meat products that persists throughout processing of products), $N_{3}$ is the TSD factor event (the survival of the virus in meat products after processing through international transportation), and $N_{4}$ is the passenger event, which represents nonintercepted passengers who illegally carry meat products contaminated with the FMD virus. $N_{1}, N_{2}$, and $N_{3}$ are so-called FMD factor events. $N_{2}$ and $N_{3}$ are the survival of the virus in meat throughout different types of procedure and in different meat products, which can be set to be independent of $N_{1}$. In practice, the FMD factors events, $N_{1}, N_{2}$, and $N_{3}$, are generally independent of the passenger event $N_{4}$. By using the decomposition of the joint probability and the independent mechanism among events, the probability in Equation (1) is expressed as:

$$
P(\text { area })=P\left(N_{1}\right) P\left(N_{2} \times N_{3}\right) P\left(N_{4}\right) .
$$

Thus, the $P($ area $)$ can be derived by separately modeling the conditional probabilities of $N_{1}$, $N_{2} \times N_{3}$, and $N_{4}$. The appropriate probability distributions and models are proposed to simulate the value of $P\left(N_{1} \mid\right.$ area $), P\left(N_{2} \times N_{3}\right)$, and $P\left(N_{4} \mid\right.$ area $)$. Under the validity of the proposed models, the values of the probabilities were repeatedly generated 10,000 times through a Monte Carlo simulation in the @RISK ${ }^{\mathrm{TM}(11)}$ and Microsoft Excel $^{\mathrm{TM}}$ spreadsheet software. The 10,000 iterations in our simulation study was sufficient for convergence of the three statistics monitored (less than $1.5 \%$ change of the mean, standard deviation, and percentiles in 5\% increments) on the output distributions.

\subsection{Data}

The data used in this study were from the records of passengers entering Taiwan through the Taoyuan International Airport (TPE) between July 2004 and June 2006. The related recorded variables, such as the month of intercepted passengers' arrival, the areas of origin of the illegally carried meat products, and the interception method that violating passengers are intercepted either by Customs or detective dogs, were provided by the animal quarantine authority of the Bureau of Animal and Plant Health Inspection and Quarantine (BAPHIQ). The term "intercepted" is used to describe the condition that passengers who carry illegal biological products are caught by either detective dogs or a Customs officer through inspection. The information of arriving passengers was obtained from the immigration office, National Police Agency. The reports of cases of cloven-hoofed animals affected with FMD, number of FMD susceptible animals, and number of 
cloven-hoofed animals at risk from $\mathrm{OIE}^{(12)}$ and Food Agriculture Organization ${ }^{(13,14)}$ were used for estimation of area prevalence of FMD and for further analyses. After examining the violation records and keeping the privacy of the reference countries, the areas of origin of the meat products in some Asian countries were divided into two main areas: area $\mathrm{A}$ and area $\mathrm{B}$, based on their relative violation numbers for this study.

\subsection{Modeling the Prevalence of FMD}

The prevalence of FMD-infected animals in two areas of origin, that is, $P\left(N_{1} \mid\right.$ area $)$, were modeled, mainly based on the period prevalence and the duration of FMD viremia. To simulate the prevalence of FMD, the beta and pert distributions were separately specified for the period prevalence and the duration of viremia. The value of the beta distribution is between 0 and 1 and the parameters of the beta distribution $\alpha$ and $\beta$ control the shape of the distribution. In practice, the beta distribution is often used to describe the uncertainty about the probability of occurrence of an event, and the pert distribution is a special form of the beta distribution. The period prevalence of each area can be expressed as $\operatorname{Beta}\left(x_{1}+1, n_{1}-x_{1}+1\right)$, where $x_{1}$ is the annual average number of cases of cloven-hoofed animals affected with FMD and $n_{1}$ is the annual average number of total population of cloven-hoofed animals at risk in the area of origin. The parameters $x_{1}$ and $n_{1}$ in two areas based on our data are shown in Table I. As for the parameters of pert distribution, the study by Sanson ${ }^{(15)}$ estimated that the minimum, mode, and maximum of viremia were 6,16 , and 25 days. Thus, the values of $P\left(N_{1} \mid\right.$ area $)$ can be generated from the following distribution:

$$
\operatorname{Beta}\left(x_{1}+1, n_{1}-x_{1}+1\right) \times \operatorname{Pert}((6,16,25) / 365) \text {. }
$$

\subsection{Probability of Commodity and TSD Factors}

Depending on the different types of meat processing, the probability $P\left(N_{2} \times N_{3}\right)$ is calculated based on the conditional probability $P\left(N_{2} \times N_{3}\right.$ | meat) and probabilities of different types of meat products from the conditional decomposition of joint probability $P\left(N_{2} \times N_{3}\right)=\sum_{\text {meat }} P\left(N_{2} \times N_{3} \mid\right.$ meat $)$ $P($ meat $)$. Thus by calculating the product of $P\left(N_{2} \times N_{3} \mid\right.$ meat $)$ and $P($ meat $)$ for different types of meat products and summing them, we can derive the probability $P\left(N_{2} \times N_{3}\right)$. Moreover, $P\left(N_{2} \times N_{3} \mid\right.$ meat $)$ is written as the product of $P\left(N_{2} \mid\right.$ meat $)$ and $P\left(N_{3} \mid\right.$ meat $)$ by assuming independence between the factors $N_{2}$ and $N_{3}$, given different types of meat products. Thus, by calculating $P\left(N_{2} \mid\right.$ meat $), P\left(N_{3} \mid\right.$ meat $)$, and $P($ meat $)$ for different types of meat products, we can obtain probability of commodity and TSD factors $P\left(N_{2} \times N_{3}\right)$. The intercepted products can be classified as four types of meat products according to the processing: chilling type, that is, processed with a chilling procedure, for example, chilled meat, etc.; curing type, that is, processed with chilling and curing procedures, for example, meatball, steak, etc.; drying type, that is, processed with chilling, curing, and drying procedures, for example, jerky, dried meat, etc.; steaming type, that is, processed with chilling, curing, drying, and steaming procedures, for example, ham, Chinese's ham, hot dog, bacon, sausages, meat stuffing, etc. The risk of FMD entrance is different based on the different types of meat products; thus we have to simulate them. The probabilities for different types of meat products contaminated with the FMD virus were generated via Dirichlet distribution. $\operatorname{Dirichlet}\left(x_{21} / n_{2}, x_{22} / n_{2}, x_{23} / n_{2}, x_{24} / n_{2}\right)$ is specified with $x_{2 i}$ s being the weight of different intercepted meat products, and $n_{2}$ being the total weight of intercepted meat products. The conditional probability

Table I. Data ${ }^{\mathrm{a}}$ of FMD Cases, FMD Susceptible Animals, and Population of Cloven-Hoofed Animals in A and B Two Main Areas

\begin{tabular}{|c|c|c|c|}
\hline Areas & MD Cases & & $\begin{array}{r}\text { Popu } \\
\text { Clover } \\
\text { An }\end{array}$ \\
\hline & & & \\
\hline \multicolumn{4}{|c|}{$\begin{array}{l}\text { a Data sources: } \\
\text { 1. OIE Regional Representation for Asia and the Pacific, } 2005 \text {. } \\
\text { http://www.oie-jp.org/information/foot_and_mouth/se_asia/index. } \\
\text { html;http://www.oie-jp.org/information/foot_and_mouth/e_asia/inde } \\
\text { html. } \\
\text { 2. OIE Foot-and-Mouth Disease Website Reported Outbreaks, } \\
\text { 2005. } \\
\text { http://www.oie.int/wahid-prod/public.php?page = disease_immedia } \\
\text { te_summary\&selected_year=2005. } \\
\text { 3. Ministry of Agriculture of the People's Republic of China } \\
\text { http://www.agri.gov.cn/sjzl/nynj/NYNJ200502.pdf. } \\
\text { b Average heads (2000-2005). } \\
\text { c Average heads (2000-2005). }\end{array}$} \\
\hline
\end{tabular}


$P\left(N_{2} \mid\right.$ meat $)$ was the probability of the existence of the FMD virus after meat processing procedures for different types of meat products, and was estimated by using the beta distribution. $\operatorname{Beta}\left(\alpha_{i}, \beta_{i}\right)$ is specified to generate the rate of viral denaturizing during different meat processing methods, $i=1$, $2,3,4$. The parameters used in the beta distribution were obtained based on the experimental results of Chou and $\mathrm{Yang}^{(8)}$ regarding the survival of the FMD virus in meat. According to the study, meat is processed with a single independent procedure every time. The means and standard deviations of the rate of degradation of the FMD virus in pork sausages are 0.233 and 0.151 during the chilling procedure, 0.133 and 0.207 during the curing procedure, 0.433 and 0.082 during the drying procedure, and 0.633 and 0.234 during the steaming procedure. By using the estimated means and standard deviations, we can solve the equations $u=\alpha / .(\alpha+\beta)$ and $\sigma^{2}=\alpha \beta /\left[(\alpha+\beta)^{2}(\alpha+\beta+1)\right]$ of the beta distribution and obtain the estimated parameters, $\alpha$ and $\beta$. The probability of survival of the virus after a single process is then estimated by $\lambda_{i}=1-\operatorname{Beta}\left(\alpha_{i}\right.$, $\beta_{i}$ ). The probability of survival of the virus after two or more processes is estimated by the product of the corresponding probabilities of each single process. The formulations and corresponding derived parameters for the four types of meat are showed in Table II.

The TSD factor, $N_{3}$, mainly concerns the survival of the FMD virus after meat products leave the processing factory to market shelves and are then carried by passengers arriving at TPE. $N_{3}$ consists of the TSD time of contaminated meat products $(r)$ and the intrinsic survival time of the FMD virus in meat products $(T)$. In this study, the triangular distribution was used to approximate the TSD time, $r$. Based on several TPE Customs officers' expert opinion on international transportation, the mode, and expiry time are 3 and 10 days for chilled meat, 3 and 15 days for cured meat, and 10 and 30 days for dried and steamed meat, respectively. Thus the estimated parameters in the triangular distribution, minimum, mode, and maximum times are 0,3 , and 10 days for chilled meat, 0,3 , and 15 days for cured meat, and 0,10 , and 30 days for dried and steamed meat. From the empirical distributions of TSD times for the different types of meat products carried by passengers, the triangular distribution was shown to be appropriate. As for the survival time of the FMD virus in meat products, the exponential distribution $\operatorname{Exp}\left(t_{\mu}\right)$ was proposed, where $t_{\mu}$ was the mean survival time. A pert distribution was further specified to generate the possible values of $t_{\mu}$. From the analyses of Farez and Morley ${ }^{(16)}$ and DEFRA, ${ }^{(17)}$ the survival time of the FMD virus in meat products ranged from 1 to 190 days. The minimum, mode, and maximum days were 1,10 , and 30 days for chilled meat, 1,30 , and 60 days for cured meat, 1, 112, and 182 days for dried meat, and 1,112 , and 190 days for steamed meat. These summary statistics were used as the parameters in the pert distribution to generate the possible values of $t_{\mu}$. Thus, based on the model construct for the above processes, $P\left(N_{3} \mid\right.$ meat $)$ is calculated as the probability that the intrinsic survival time of the FMD virus in meat products is larger than the TSD time of contaminated meat products:

$$
P(T>r)=\int_{r}^{\infty} \frac{1}{t_{\mu}} e^{-\frac{s}{t_{\mu}}} d s=e^{-\frac{r}{t_{\mu}}}
$$

Table II. Survival of FMD Virus and Illegally Carried Meat Products Intercepted at Taoyuan International Airport

\begin{tabular}{llrr}
\hline & & \multicolumn{2}{c}{ Intercepted Meat $(\mathrm{kg})^{\mathrm{b}},\left(x_{2}\right)^{\mathrm{c}}$} \\
\cline { 2 - 4 } Types of Meat & \multicolumn{1}{c}{ Survival Rate ${ }^{\mathrm{a}}$} & Area A & Area B \\
\hline Chilling & $\lambda_{1}=1-\operatorname{Beta}(1.593,5.245)$ & 28.6 & 12.5 \\
Curing & $\lambda_{1} \lambda_{2}=\lambda_{1}(1-\operatorname{Beta}[0.225,1.466])$ & 2.3 & 14.3 \\
Drying & $\lambda_{1} \lambda_{2} \lambda_{3}=\lambda_{1} \lambda_{2}(1-\operatorname{Beta}[15.377,20.136])$ & $2,138.9$ & $1,337.4$ \\
Steaming & $\lambda_{1} \lambda_{2} \lambda_{3} \lambda_{4}=\lambda_{1} \lambda_{2} \lambda_{3}(1-$ Beta[2.053,1.190]) & $1,350.6$ & $5,780.7$ \\
\hline
\end{tabular}

${ }^{\mathrm{a}}$ Experiment results from Reference 8 .

${ }^{\mathrm{b}}$ Chilling: chilled meat. Curing type: meatball, steak, etc. Drying: jerky, dried meat, etc. Steaming: ham, Chinese ham, hot dog, bacon, sausages, meat stuffing, etc.

${ }^{\mathrm{c}} n_{2}$ : total intercepted meat weight (area A: $3,522.4 \mathrm{~kg}$, area B: 7,144.9 kg). 


\subsection{Probability of the Passenger Event}

Even though all international passengers arriving in Taiwan at TPE must pass through Customs, some passengers are randomly inspected by beagles. Since the information about nonintercepted passengers who illegally carry cloven-hoofed meat products is not available, a relationship between $P\left(N_{4} \mid\right.$ area $)$ and the probability of intercepted passengers is further suggested by the following. Let $D$ denote intercepted passengers $(D=1)$ versus nonintercepted passengers $(D=0)$, and $E$ the status of passengers who carry $(E=1)$ versus those who do not carry $(E=0)$ meat products contaminated with the FMD virus. For the conditional probability $P\left(N_{4} \mid\right.$ area $)$, that is, $P(D=0, E=1 \mid$ area $)$, it is reasonable to set the ratio of $P(D=0, E=1 \mid$ area $)$ and $P(D=0$, $E=0 \mid$ area $)$ proportional to the odds, say, $\theta($ area $)=$ $\frac{P(D=1 \mid \text { area })}{P(D=0 \mid \text { area })}$ of $D=1$ versus $\{D=0\}$. The odds indicate the relative relationship between the probability of passengers intercepted and that of passengers nonintercepted from a specific area. Moreover, the suggested relationship can then be expressed as:

$$
\frac{P(D=0, E=1 \mid \text { area })}{P(D=0, E=0 \mid \text { area })}=\alpha \cdot \theta(\text { area })
$$

where the multiplier $\alpha$ is a positive constant and can be substituted by the empirical value, say, $\hat{\alpha}$. That means we assume that the ratio of $P(D=0$, $E=1 \mid$ area $)$ and $P(D=0, E=0 \mid$ area $)$ is proportional to the ratio of $P(D=1 \mid$ area $)$ and $P(D=0 \mid$ area $)$. From model (5), we can obtain the derivative (see the Appendix):

$$
\begin{aligned}
P(D & =0, E=1 \mid \text { area }) \\
& =\frac{\alpha \theta(\text { area })}{(1+\theta(\text { area }))(1+\alpha \theta(\text { area }))} .
\end{aligned}
$$

$P(D=0, E=1 \mid$ area $)$ is an increasing function of $\alpha$, which indicates the status of interception at TPE. As for the odds function $\theta$ (area), two other important variables, which include the month (mon) of study period and the inspection (ins) were considered. Logistic regression analysis was applied to model $P(D=1 \mid$ mon, ins, area $)$ as below:

$$
\begin{aligned}
& P(D=1 \mid \text { mon, ins, area })= \\
& \left.\frac{\exp \left(\beta_{0}+\sum_{i=1}^{11} \beta_{1 i} \delta_{i}(\text { mon })+\beta_{2} \text { ins }+\beta_{3} \text { area }\right)}{1+\exp \left(\beta_{0}+\sum_{i=1}^{11} \beta_{1 i} \delta_{i}(\text { mon })+\beta_{2} \text { ins }+\beta_{3} \text { area }\right)}\right)
\end{aligned}
$$

where $\beta_{l}$ s are the effects of the corresponding variables, and $\delta_{i}($ mon $)=1$ if mon $=i$ and 0 if not; the variable ins is defined to be 1 if the meat products were intercepted by beagles and 0 if not; the variable area is given by 1 if passengers came from area $\mathrm{A}$ and 0 if not. In the above model, December was treated as the reference month. Based on the data $\left\{\left(D_{i}\right.\right.$, mon $_{i}$, ins $_{i}$, area $\left.\left._{i}\right): i=1, \ldots, n\right\}$, where $n$ is the sample size, and the logistic regression model (7), the maximum-likelihood estimates, say, $\left(\hat{\beta}_{0}, \hat{\beta}_{11}, \ldots, \hat{\beta}_{111}, \hat{\beta}_{2}, \hat{\beta}_{3}\right)$ for $\left(\beta_{0}, \beta_{11}, \ldots, \beta_{111}, \beta_{2}, \beta_{3}\right)$ can be obtained. The probability $P(D=1 \mid$ mon, ins, area $)$ is then estimated by $\hat{P}(D=1 \mid$ mon, ins, area $)$ with $\left(\hat{\beta}_{0}, \hat{\beta}_{11}, \ldots, \hat{\beta}_{111}, \hat{\beta}_{2}, \hat{\beta}_{3}\right)$ substituting for $\left(\beta_{0}\right.$, $\left.\beta_{11}, \ldots, \beta_{111}, \beta_{2}, \beta_{3}\right)$. By using the empirical probability $\hat{P}($ mon $=i$, ins $=j \mid$ area $), i=1, \ldots, 12 ; j=$ $0,1, P(D=1 \mid$ area $)$, and $\theta($ area $)$ are calculated via

$$
\begin{gathered}
\hat{P}(D=1 \mid \text { area })=\sum_{i=1}^{12} \sum_{j=0}^{1} \hat{P}(D=1 \mid \text { mon }=i, \\
\text { ins }=j, \text { area }) \hat{P}(\text { mon }=i, \text { ins }=j \mid \text { area })
\end{gathered}
$$

and

$$
\hat{\theta}(\text { area })=\frac{\hat{P}(D=1 \mid \text { area })}{1-\hat{P}(D=1 \mid \text { area })} .
$$

To simulate the values of $P\left(N_{4} \mid\right.$ area $)$ in Equation (6), the pert distribution was specified with 0.5 , 1 , and 2 being assigned to the multiplier $\alpha$, and the odds function $\theta$ (area) being substituted by the estimate $\hat{\theta}($ area $)$ in Equation (9).

\section{RESULTS}

There were 9,310,011 and 9,877,124 passengers arriving in Taiwan through the TPE airport during the study period of July 2004 to June 2005 and July 2005 to June 2006, respectively. For the study period of July 2004 to June 2005, a total of 3,399 passengers (violation risk: $3.65 \times 10^{-4}$ ) illegally carrying meat products of cloven-hoofed animals were intercepted and 7,345 passengers (violation risk: $7.44 \times 10^{-4}$ ) from July 2005 to June 2006 . The violation numbers of area A passengers and area B passengers were 882 (violation risk: $2.20 \times 10^{-4}$ ) and 1,838 (violation risk: $\left.9.65 \times 10^{-4}\right)$, respectively, from July 2004 to June 2005, and 2,210 (violation risk: $6.09 \times 10^{-4}$ ) and 3,651 (violation risk: $2.28 \times 10^{-3}$ ) for area A passengers and area B passengers from July 2005 to June 2006. From the records, 1,778 and 942 violating passengers 
were intercepted separately by beagles from 567,148 passengers and Customs from 5,918,967 passengers of the study period of July 2004 to June 2005, and 4,554 and 1,307 violating passengers intercepted separately by beagles from 959,048 passengers and Customs from 5,226,326 passengers during July 2005 to June 2006.

The probability of the passenger event was simulated using the relationship between $P\left(N_{4} \mid\right.$ area $)$ and the odds $\theta$ (area) in Equation (6). Under the validity of the logistic regression model in Equation (7), $P(D=1 \mid$ mon, ins, area $)$ was estimated as:

$$
\begin{aligned}
& \operatorname{Logit} \hat{P}(D=1 \mid \text { mon, ins, area }) \\
& =-7.53+\sum_{j=1}^{11} \hat{\beta}_{1 j} \delta_{j}(\text { mon })-1.21 \text { area }+2.77 \text { ins. }
\end{aligned}
$$

The effects of the variables ins and area on the probability were significant with a $p$-value of $<0.0001$. From the residual analysis and the Pearson chi-square test for the goodness of fit, the fitting model was shown to be appropriate $(p<0.0001)$. Moreover, the probabilities of intercepting passengers in January and February were significantly greater than in December $(p<0.0001)$. However, probabilities in other months were not significantly different from that of December. The odds of intercepting passengers by beagles and Customs range separately from $0.30 \times 10^{-3}$ to $2.15 \times 10^{-3}$ and $0.09 \times 10^{-3}$ to $0.19 \times 10^{-3}$ for passengers from area $\mathrm{A}$, and range from $5.20 \times 10^{-3}$ to $8.60 \times 10^{-3}$ and $0.21 \times 10^{-3}$ to $0.37 \times 10^{-3}$ for passengers from area B in different months from July 2004 to June 2005. The odds of intercepting passengers by beagle and Customs range separately from $0.92 \times 10^{-3}$ to $4.44 \times 10^{-3}$ and $0.09 \times 10^{-3}$ to $0.80 \times 10^{-3}$ for passengers from area $\mathrm{A}$, and range from $4.53 \times 10^{-3}$ to $12.4 \times 10^{-3}$ and $0.26 \times 10^{-3}$ to $0.85 \times 10^{-3}$ for passengers from area $\mathrm{B}$ in different months from July 2005 to June 2006 (Table III). The odds of intercepting passengers from area B were 3.35 times $\left(\mathrm{e}^{1.21}\right)$ higher than that of area A passengers. The odds of intercepting passengers by beagles were about 15.96 times $\left(\mathrm{e}^{2.77}\right)$ higher than the odds of intercepting passengers by Customs. The results for the empirical probability $\hat{P}($ mon $=i$, ins $=j \mid$ area $), i=1, \ldots, 12$; $j=0,1$ are shown in Table IV. The derived estimates $\hat{\theta}($ area $)$ were $4.86 \times 10^{-4}$ and $2.06 \times 10^{-3}$ for area $\mathrm{A}$ and area $\mathrm{B}$, respectively. The probabilities of the passenger event were then generated from the pert distributions: Pert $\left(2.43 \times 10^{-4}[\alpha=0.5]\right.$, $\left.4.86 \times 10^{-4}[\alpha=1], 9.70 \times 10^{-4}[\alpha=2]\right)$ for area $\mathrm{A}$ and Pert $\left(1.03 \times 10^{-3}[\alpha=0.5], 2.06 \times 10^{-3}[\alpha=1]\right.$, $\left.4.12 \times 10^{-3}[\alpha=2]\right)$ for area B.

By implementing 10,000 iterated simulations, the results in Table $\mathrm{V}$ showed that the median value of the probability for the FMD virus risk associated with FMD factors from area A $\left(4.92 \times 10^{-8}\right)$ was significantly lower than that from area B $\left(7.33 \times 10^{-6}\right.$; about 149 times) because of the significantly lower prevalence in area A. Furthermore, the probability of the passenger event $\left(N_{4}\right)$ from area $\mathrm{A}\left(5.13 \times 10^{-4}\right)$ was lower than that from area B $\left(2.20 \times 10^{-3}\right.$; about four times). In total, the probability of the FMD virus entering Taiwan through air passenger violations at the TPE airport from area A $\left(2.45 \times 10^{-11}\right)$ was significantly lower than that from area $\mathrm{B}\left(1.58 \times 10^{-8}\right)$. By considering the different processing methods of the violation products, the probability associated with chilled, cured, dried, and steamed meat products from area A were $4.12 \times 10^{-13}, 7.07 \times 10^{-14}$, $1.96 \times 10^{-11}$, and $3.71 \times 10^{-12}$, and were $9.81 \times 10^{-11}$, $1.17 \times 10^{-10}, 6.49 \times 10^{-9}$, and $8.35 \times 10^{-9}$ from area B. Dried and steamed meat products have higher risk values for the survival of the FMD virus than chilled and cured meat products in this study for both areas.

\section{DISCUSSION}

It is well recognized that the FMD virus is likely to be present in meat from animals that were viremic at the time of slaughtering, and the length of the virus survival in meats can vary depending on different environmental factors. ${ }^{(3)}$ Based on experimental results and expert advice, this study developed a flexible model to characterize the probability for FMD virus entrance associated with passengers who illegally carry meat products through TPE airport into Taiwan. Parameters for different types of meat products and different processing conditions can be modified once a newly developed result is provided and can be simulated accordingly.

This study retrieved cases of cloven-hoofed animals affected with the FMD virus and their corresponding total number of animal population at risk in six years (2000-2005) based on OIE and FAO reports to calculate the year-prevalence of FMD for the prediction model. The period prevalence is the number of cases of a disease that occur during a year as a percentage of the total or average total number of animals at risk during the same period. In practice, FMD is a highly infectious airborne disease. 
Table III. The Parameter Estimates and Odds of Intercepted Passengers by Months, Origin Areas, and Inspection Methods During Years 2004 and 2006

\begin{tabular}{|c|c|c|c|c|c|c|c|c|c|}
\hline \multirow[b]{3}{*}{ Month } & \multirow{3}{*}{$\begin{array}{l}\text { Estimates } \\
\hat{\beta}_{1 j}\end{array}$} & \multicolumn{8}{|c|}{ Odds $^{\mathrm{a}}$} \\
\hline & & \multicolumn{2}{|c|}{ Area A and Customs } & \multicolumn{2}{|c|}{ Area A and Beagle } & \multicolumn{2}{|c|}{ Area B and Customs } & \multicolumn{2}{|c|}{ Area B and Beagle } \\
\hline & & Year $1^{\mathrm{c}}$ & Year $2^{\mathrm{d}}$ & Year $1^{\mathrm{c}}$ & Year $2^{\mathrm{d}}$ & Year $1^{\mathrm{x}}$ & Year $2^{\mathrm{d}}$ & Year $1^{\mathrm{c}}$ & Year $2^{\mathrm{d}}$ \\
\hline Jul & $\begin{array}{c}-0.6452 \\
(0.0631)\end{array}$ & 0.10 & 0.07 & 0.62 & 1.13 & 0.36 & 0.28 & 5.26 & 4.53 \\
\hline Aug & $\begin{array}{c}-0.5805 \\
(0.0612)\end{array}$ & 0.14 & 0.11 & 0.55 & 0.92 & 0.26 & 0.41 & 5.20 & 4.88 \\
\hline Sep & $\begin{array}{c}-0.5003 \\
(0.0636)\end{array}$ & 0.08 & 0.09 & 0.30 & 1.49 & 0.21 & 0.26 & 6.38 & 7.67 \\
\hline Oct & $\begin{array}{c}-0.2991 \\
(0.0585)\end{array}$ & 0.12 & 0.09 & 0.40 & 2.81 & 0.29 & 0.30 & 5.50 & 7.13 \\
\hline Nov & $\begin{array}{c}-0.0461 \\
(0.0545)\end{array}$ & 0.12 & 0.30 & 1.07 & 3.29 & 0.33 & 0.64 & 7.71 & 7.15 \\
\hline Dec & - b & 0.14 & 0.33 & 1.03 & 3.32 & 0.26 & 0.76 & 5.84 & 8.66 \\
\hline Jan & $\begin{array}{c}0.3002 \\
(0.0497)\end{array}$ & 0.19 & 0.80 & 1.15 & 3.92 & 0.29 & 0.65 & 7.90 & 11.8 \\
\hline Feb & $\begin{array}{c}0.1736 \\
(0.0494)\end{array}$ & 0.17 & 0.29 & 2.15 & 4.44 & 0.28 & 0.59 & 7.23 & 12.4 \\
\hline Mar & $\begin{array}{c}0.0680 \\
(0.0493)\end{array}$ & 0.11 & 0.21 & 1.55 & 3.29 & 0.23 & 0.71 & 7.94 & 11.6 \\
\hline Apr & $\begin{array}{c}-0.0656 \\
(0.0510)\end{array}$ & 0.11 & 0.29 & 1.41 & 1.73 & 0.34 & 0.85 & 8.60 & 9.07 \\
\hline May & $\begin{array}{c}-0.2751 \\
(0.0526)\end{array}$ & 0.09 & 0.23 & 1.21 & 1.92 & 0.30 & 0.55 & 6.25 & 7.01 \\
\hline Jun & $\begin{array}{c}-0.3005 \\
(0.0527)\end{array}$ & 0.10 & 0.12 & 1.59 & 2.20 & 0.37 & 0.48 & 7.21 & 5.44 \\
\hline
\end{tabular}

Logit $\hat{P}(D=1 \mid$ mon, ins, area $)=-7.53+\sum_{j=1}^{11} \hat{\beta}_{1 j} \delta_{j}($ mon $)-1.21$ area +2.77 ins

$(0.043) \quad(0.0226)(0.0248)$.

a $\times 10^{-3}$.

${ }^{\mathrm{b}}$ Reference month.

${ }^{c}$ Year 1: 2004/07 2005/06.

${ }^{\mathrm{d}}$ Year 2: 2005/07 2006/06.

The speed of transmission is fast and thus culling of the whole herd is usually recommended and enacted in order to destroy all cloven-hoofed animals in a herd, in case of susceptible animals being left in the field that can easily contract the FMD virus and cause other outbreaks. Thus, it might be reasonable to use heads of the total susceptible cloven-hoofed animals in the outbreak herd as numerator to calculate the prevalence of FMD for a more conservative study. According to the above-mentioned statement, the prevalence of FMD with susceptible animals is about six times of that with cases of animals in area $\mathrm{A}$ and is about five times in area $\mathrm{B}$ after simulation (Tables V and VI).

The value of the beta distribution is between 0 and 1 and the parameters that control the shapes can describe the uncertainty. In this study, beta distribution was used to describe the value of period preva- lence, and the distribution of the duration of viremia was based on the study by Sanson. ${ }^{(15)}$ Since the above cases and animal populations were reported voluntarily and no other informative reports were accessible, the calculated prevalence is thus imprecise and may be underestimated.

Different types of intercepted meat products have their specific weight of packet/unit and the number of the FMD virus in different contaminated packets/units therefore differs. For each type of meat product, the Dirichlet distribution, based on Christensen et al.'s study, ${ }^{(18)}$ was used to characterize the proportions of weight of illegally imported meat products in the Monte Carlo simulation. Thus, meat with the FMD virus by weight was estimated.

Food processing stages of the majority of the violation meat products were found to be similar. This is because of the areas A and B chosen for this study 


\begin{tabular}{lcccc}
\hline & \multicolumn{4}{c}{ Empirical Probability } \\
\cline { 2 - 5 } Month & Area A and Customs & Area A and Beagle & Area B and Customs & Area B and Beagle \\
\hline Jul & 8.40 & 0.81 & 8.53 & 1.14 \\
Aug & 8.19 & 0.84 & 8.73 & 1.20 \\
Sep & 7.18 & 0.84 & 7.37 & 0.85 \\
Oct & 7.53 & 0.81 & 6.81 & 1.17 \\
Nov & 6.39 & 0.95 & 6.10 & 1.08 \\
Dec & 6.62 & 0.86 & 6.41 & 1.08 \\
Jan & 6.53 & 1.28 & 6.05 & 1.01 \\
Feb & 7.28 & 0.98 & 7.93 & 1.49 \\
Mar & 7.13 & 1.28 & 6.64 & 1.72 \\
Apr & 8.02 & 1.30 & 6.92 & 1.57 \\
May & 7.48 & 1.36 & 6.96 & 1.79 \\
Jun & 6.68 & 1.23 & 5.37 & 2.08 \\
\hline
\end{tabular}

Table IV. The Empirical Probability $\hat{P}($ mon $=i$, ins $=j \mid$ area $), i$ $=1, \ldots, 12 ; j=0,1$

$\mathrm{a} \times 10^{-2}$.

Table V. Simulated Values for FMD Factors, Passenger Event, and Probability for the Risk of FMD-Contaminated Meat Products to Enter Taiwan per Year

\begin{tabular}{|c|c|c|c|c|}
\hline Area & Factors/Event/Probability & 5th Percentile & Median & 95th Percentile \\
\hline \multirow[t]{8}{*}{ A } & Prevalence of FMD ${ }^{\mathrm{a}}$ & $1.26 \times 10^{-7}$ & $2.05 \times 10^{-7}$ & $2.79 \times 10^{-7}$ \\
\hline & Commodity and transportation & $9.09 \times 10^{-2}$ & $2.51 \times 10^{-1}$ & $4.02 \times 10^{-1}$ \\
\hline & FMD factors & $1.60 \times 10^{-8}$ & $4.92 \times 10^{-8}$ & $9.17 \times 10^{-8}$ \\
\hline & Passenger event & $3.23 \times 10^{-4}$ & $5.13 \times 10^{-4}$ & $7.60 \times 10^{-4}$ \\
\hline & Probability $(\alpha=0.5)$ & $3.88 \times 10^{-12}$ & $1.19 \times 10^{-11}$ & $2.23 \times 10^{-11}$ \\
\hline & Probability $(\alpha=1)$ & $7.76 \times 10^{-12}$ & $2.39 \times 10^{-11}$ & $4.45 \times 10^{-11}$ \\
\hline & Probability $(\alpha=2)$ & $1.55 \times 10^{-11}$ & $4.78 \times 10^{-11}$ & $8.90 \times 10^{-11}$ \\
\hline & Probability (area A) & $7.64 \times 10^{-12}$ & $2.45 \times 10^{-11}$ & $5.30 \times 10^{-11}$ \\
\hline \multirow[t]{8}{*}{ B } & Prevalence of FMD ${ }^{\mathrm{a}}$ & $3.26 \times 10^{-5}$ & $5.22 \times 10^{-5}$ & $7.12 \times 10^{-5}$ \\
\hline & Commodity and transportation & $4.62 \times 10^{-2}$ & $1.45 \times 10^{-1}$ & $3.27 \times 10^{-1}$ \\
\hline & FMD factors & $2.14 \times 10^{-6}$ & $7.33 \times 10^{-6}$ & $1.79 \times 10^{-5}$ \\
\hline & Passenger event & $1.37 \times 10^{-3}$ & $2.20 \times 10^{-3}$ & $3.24 \times 10^{-3}$ \\
\hline & Probability $(\alpha=0.5)$ & $2.21 \times 10^{-9}$ & $7.58 \times 10^{-9}$ & $1.85 \times 10^{-8}$ \\
\hline & Probability $(\alpha=1)$ & $4.41 \times 10^{-9}$ & $1.51 \times 10^{-8}$ & $3.70 \times 10^{-8}$ \\
\hline & Probability $(\alpha=2)$ & $8.80 \times 10^{-9}$ & $3.02 \times 10^{-8}$ & $7.38 \times 10^{-8}$ \\
\hline & Probability (area B) & $4.28 \times 10^{-9}$ & $1.58 \times 10^{-8}$ & $4.34 \times 10^{-8}$ \\
\hline
\end{tabular}

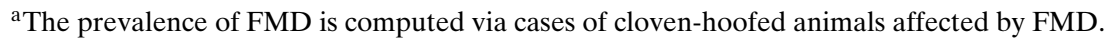

being located in Asia and those violation meat products were more or less related to the Chinese customs of use. Thus, application of the production processes of pork sausages ${ }^{(8)}$ has the advantage of simulating many similar food production processes. In Chou and Yang's ${ }^{(8)}$ study, the virus inactivation is based on the detection of only one strain of viable virus, which underestimates the risk because of method sensitivity; degradation will overestimate the risk due to the detection viral residues based on RT-PCR results of the RNA genome. However, for a more conservative approach, the degradation was recommended to take into consideration. The survival of the FMD virus was estimated by the beta distribution and the means and standard deviations of degradation were used to estimate parameters of $\alpha$ and $\beta$. Different degradation rates of the virus and uncertainties in different meat products are shown via different parameters of $\alpha$ and $\beta$. Another limitation of the study is that the data for the FMD virus used in this study are only for one specific strain (strain O Taiwan97). Parameters for other strains may also need to be fitted into a current model once other epidemiologic strains are specified and their data become available. Different conditions such as $\mathrm{pH}$ values and temperatures ${ }^{(19,20)}$ influencing the survival of the FMD virus need also to be considered.

As for the probability values of the TSD factor, a triangular distribution was used to predict the transportation time $(r)$ of meat products. Because the 
Table VI. Simulated Values for FMD Factors, Passenger Event, and Probability for the Risk of FMD-Contaminated Meat Products to Enter Taiwan per Year

\begin{tabular}{|c|c|c|c|c|}
\hline Area & Factors/Event/Probability & 5th Percentile & Median & 95th Percentile \\
\hline A & $\begin{array}{l}\text { Prevalence of FMD } \\
\text { Commodity and transportation } \\
\text { FMD factors } \\
\text { Passenger event } \\
\text { Probability }(\alpha=0.5) \\
\text { Probability }(\alpha=1) \\
\text { Probability }(\alpha=2) \\
\text { Probability (area A) }\end{array}$ & $\begin{array}{l}7.44 \times 10^{-7} \\
8.78 \times 10^{-2} \\
9.56 \times 10^{-8} \\
3.22 \times 10^{-4} \\
2.32 \times 10^{-11} \\
4.64 \times 10^{-11} \\
9.27 \times 10^{-11} \\
4.56 \times 10^{-11}\end{array}$ & $\begin{array}{l}1.20 \times 10^{-6} \\
2.51 \times 10^{-1} \\
2.87 \times 10^{-7} \\
5.18 \times 10^{-4} \\
6.97 \times 10^{-11} \\
1.39 \times 10^{-10} \\
2.79 \times 10^{-10} \\
1.44 \times 10^{-10}\end{array}$ & $\begin{array}{l}1.64 \times 10^{-6} \\
4.03 \times 10^{-1} \\
5.35 \times 10^{-7} \\
7.61 \times 10^{-4} \\
1.30 \times 10^{-10} \\
2.60 \times 10^{-10} \\
5.19 \times 10^{-10} \\
3.11 \times 10^{-10}\end{array}$ \\
\hline B & $\begin{array}{l}\text { Prevalence of FMD } \\
\text { Commodity and transportation } \\
\text { FMD factors } \\
\text { Passenger event } \\
\text { Probability }(\alpha=0.5) \\
\text { Probability }(\alpha=1) \\
\text { Probability }(\alpha=2) \\
\text { Probability (area B) }\end{array}$ & $\begin{array}{l}1.52 \times 10^{-4} \\
4.59 \times 10^{-2} \\
1.02 \times 10^{-5} \\
1.39 \times 10^{-3} \\
1.05 \times 10^{-8} \\
2.11 \times 10^{-8} \\
4.21 \times 10^{-8} \\
2.07 \times 10^{-8}\end{array}$ & $\begin{array}{l}2.43 \times 10^{-4} \\
1.45 \times 10^{-1} \\
3.41 \times 10^{-5} \\
2.20 \times 10^{-3} \\
3.52 \times 10^{-8} \\
7.03 \times 10^{-8} \\
1.40 \times 10^{-7} \\
7.31 \times 10^{-8}\end{array}$ & $\begin{array}{l}3.31 \times 10^{-4} \\
3.26 \times 10^{-1} \\
8.42 \times 10^{-5} \\
3.24 \times 10^{-3} \\
8.70 \times 10^{-8} \\
1.74 \times 10^{-7} \\
3.47 \times 10^{-7} \\
2.00 \times 10^{-7}\end{array}$ \\
\hline
\end{tabular}

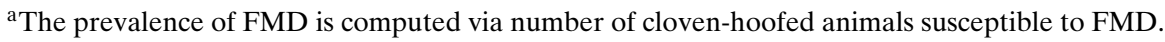

parameters of triangular distribution are minimum, mode, and maximum of the TSD time, the uncertainty of the TSD time in different meat products can be assessed. Lognormal distribution is also a feasible method for current study since the TSD time for meat carried by passengers has a right-skewed characteristic. The curve after lognormal transformation is smooth and well fitted. The parameters in the lognormal distribution were $\mu$ and $\sigma$ and were used to estimate approximate results. After simulations, the results of the lognormal distributions were similar to those from using triangular distribution (for area A, 0.260 vs. 0.251 , for area B, 0.150 vs. 0.145 ).

The situation that we are concerned with is that the FMD virus still exists in the meat products carried by passengers arriving in Taiwan. Thus, instead of simply calculating the survival time of the FMD virus in meat products $P(T>0)$, the probability $P(T>r)$ also takes into account the survival time of the FMD virus in meat products after passengers arrive. An exponential distribution was used to characterize the survival time of the FMD virus in meat products. This distributional assumption can be generalized to some other parametric distributions, such as the Weibull distribution, the gamma distribution, or the empirical distribution, if certain experiments related to the survival time of the FMD virus in meat products were conducted.

Meat products are not allowed to be carried through Customs. Illegal carriage of meat products by passenger may or may not be intercepted. Among the nonintercepted meat products, those contaminated with the FMD virus are the one we are concerned with. $N_{1}, N_{2}$, and $N_{3}$ denote the risk of the meat products contaminated with FMD virus before they are carried into Taiwan. As they are not intercepted, the risk still exists. That is why we must consider the passenger event $N_{4}$. The logistic regression model was used to obtain the estimate of the probability of intercepting passengers from different areas. The variables of year and month were considered and both of them found to be significant ( $p$ values both $<0.0001)$. However, the data we have from two years of sampling are relatively too few to represent the long-term performance trend. According to a previous study, the month of Chinese Lunar New Year had significant contributions to the violations. ${ }^{(2)}$ Thus, the current model only discusses the month variable and excluded the year variable. $0.5,1$, and 2 were the number assigned to the multiplier $\alpha$ describing the decreasing, unchanged, and increasing relationship between the ratio of $P(D=0$, $E=1 \mid$ area $)$ and $P(D=0, E=0 \mid$ area $)$ and $\theta$ (area), respectively. The setting of the $\alpha$ value provides indications on whether quarantine measures were effectively and strictly implemented, and also allows us to enforce better regulation rules. Depending on the enforcement of inspection in different locations, the $\alpha$ value in the model can be adjusted for a better risk estimation.

The risk of the four types of processed meat products transmitting the FMD virus in the current 
study indicates that drying and steaming have higher risk values for the survival of the FMD virus. This is because of a longer survival time for the FMD virus after the drying and steaming process (if the virus survives) than that of chilling and curing. ${ }^{(16,17)}$ Another reason is that higher quantities of dried and steamed products were found in violations. Furthermore, there were higher risks in some specific months (January-February) and it is reasonable to recommend authorities to strengthen inspection of passengers from area A and area B in the high-risk months and also enhance the beagle inspection as well.

\section{CONCLUSIONS}

The socioeconomic aspects of a country can be impacted by FMD in the international trade of animals and animal products. The above-mentioned study at these two pandemic areas may pose a potential FMD risk to Taiwan through air passenger violations. The model that we proposed provides an estimate of risk of FMD entrance by international passengers who illegally carry meat products. When more accurate disease information related to cases of FMD is released, that is to say, a better transparency in providing the disease's information, and more FMD virus survival results in commodities from more scientific evidence, the model that we proposed will be closer to the true situation for a better estimation of the risk of FMD entrance from illegally carried meat products. The current model can be used to predict FMD incurred from other areas apart from the above-mentioned two areas or it can be applied to other diseases with some modifications.

\section{ACKNOWLEDGMENTS}

The authors would like to thank the $\mathrm{Bu}$ reau of Animal and Plant Health Inspection and Quarantine (95AS-13.1.1-BQ-B3(2), 96AS-14.1.1BQ-B3(1)) and National Science Council (NSC 95313-B-002-057) for providing funding, and the Immigration Office, National Police Agency for providing information on arriving passengers. We also would like to thank Randall S. Morley from the Canadian Food Inspection Agency, Tzu-Jung Huang from the Department of Mathematics of National Taiwan University, Yi-Ting Hwang from the Department of Statistics of National Taipei University, and Chao-Chin Chang from the Graduate Institute of
Veterinary Public Health of National Chung Hsing University for their valuable suggestions.

\section{APPENDIX}

$$
\begin{aligned}
& \frac{P(D=0, E=1 \mid \text { area })}{P(D=0, E=0 \mid \text { area })}=\alpha \cdot \theta(\text { area }) \\
& \Rightarrow P(D=0, E=1 \mid \text { area }) \\
& \quad=\frac{\alpha \cdot \theta(\text { area })}{(1+\alpha \cdot \theta(\text { area }))(1+\theta(\text { area }))}
\end{aligned}
$$

Proof:

$$
\begin{aligned}
& \begin{array}{l}
P(D=0, E=1 \mid \text { area }) \\
P(D=0, E=0 \mid \text { area })
\end{array} \\
& \quad=\alpha \cdot \theta(\text { area })=\alpha \frac{P(D=1 \mid \text { area })}{P(D=0 \mid \text { area })} \\
& \Rightarrow P(D=0, E=1 \mid \text { area }) \\
& \quad=\alpha \cdot \theta(\text { area }) \cdot P(D=0, E=0 \mid \text { area }) \\
& \quad=\alpha \cdot \theta(\text { area }) \cdot(P(D=0 \mid \text { area }) \\
& \quad-P(D=0, E=1 \mid \text { area })) \\
& \quad=\alpha \cdot \theta(\text { area }) \cdot P(D=0 \mid \text { area }) \\
& \quad-\alpha \cdot \theta(\text { area }) \cdot P(D=0, E=1 \mid \text { area }) \\
& \Rightarrow P(D=0, E=1 \mid \text { area })(1+\alpha \cdot \theta(\text { area })) \\
& \quad=\alpha \cdot \theta(\text { area }) \cdot P(D=0 \mid \text { area }) \\
& \Rightarrow P(D=0, E=1 \mid \text { area }) \\
& \quad=\frac{\alpha \cdot \theta(\text { area }) \cdot P(D=0 \mid \text { area })}{(1+\alpha \cdot \theta(\text { area }))}--(\mathrm{A} .1) \\
& \quad \begin{aligned}
P(D \\
\Rightarrow
\end{aligned} \\
& \quad=0 \mid \text { area })=\frac{P(D=1 \mid \text { area })}{\theta(\text { area })} \\
& \Rightarrow P(D=0 \mid \text { area }) \cdot \theta(\text { area })=1-P(D=0 \mid \text { area }) \\
& \Rightarrow P(D=0 \mid \text { area })(1+\theta(\text { area }))=1 \\
& \Rightarrow P(D=0 \mid \text { area }) \\
& \quad 1+\theta(\text { area })
\end{aligned}
$$

By (A.1) and (A.2)

$$
\begin{aligned}
P(D & =0, E=1 \mid \text { area }) \\
& =\frac{\alpha \cdot \theta(\text { area })}{(1+\alpha \cdot \theta(\text { area }))(1+\theta(\text { area }))}
\end{aligned}
$$




\section{REFERENCES}

1. Blackwell JH. Foreign animal disease agent survival in animal products: Recent developments. Journal of American Veterinary Medical Association, 1984; 184:674679.

2. Shih TH, Chou CC, Morley RS. Monte Carlo simulation of animal-product violations incurred by air passengers at an international airport in Taiwan. Preventive Veterinary Medicine, 2005; 68:115-122.

3. Pharo HJ. Foot-and-mouth disease: An assessment of the risks facing New Zealand. New Zealand Veterinary Journal, 2002; 50:46-55.

4. Shih TH, Shen LC, Hsu CY, Chang YH, Chou CC. Violation risk of illegal animal products carried by air-passengers. Taiwan Veterinary Journal, 2006; 32(3):210-216.

5. Kitching RP, Alexandersen S. Clinical variation in foot and mouth disease: Pigs. OIE Scientific and Technical Review, 2002; 21:513-518.

6. Mahy BWJ. Foot-and-Mouth Disease Virus (pp. 133-148). Berlin/Heidelberg/New York: Springer, 2005.

7. Blackwell JH, Rickansrud D, McKercher PD, McVicar JW. Effect of thermal processing on the survival of foot-and-mouth disease virus in ground meat. Journal of Food Science, 1982; 47:388-392.

8. Chou CC, Yang SE. Inactivation and degradation of O Taiwan 97 foot-and-mouth disease virus in pork sausage processing. Food Microbiology, 2004; 21:737-742.

9. Emma H, Amie A, Miles S, John C, Eamon W, Helen C, Tracey E, Christophen M, Anthony C, Mavion WA. Quantitative assessment of the risks from illegally imported meat contaminated with foot and mouth disease virus to Great Britain. Risk Analysis, 2007; 27:187-202.

10. Amass SF, Schneider JL, Gaul AM. Evaluation of current and novel protocols for disinfection of airplane passenger footwear under simulated conditions. Preventive Veterinary Medicine, 2005; 71:127-134.

11. Anonymous. Guide to Using @RISK: Risk Analysis and Simulation Add-In for Microsoft Excel, Version 4.5. New York: Palisade Corporation, 2002.

12. OIE Regional Representation for Asia and the Pracific, 2005. Available at: http://www.oie-jp.org/information/foot_ and_mouth/se_asia/index.html.

13. FAO Global Animal Production and Health Division. 2004. Global Livestock Production and Health Atlas. Available at: http://www.fao.org/ag/aga/glipha/index.jsp.

14. FAO. Foot-and-mouth disease type Asia-1 in China, 2005. Available at: http://www.fao.org/docs/eims/upload//191450/ FMD_China_EMPRES.pdf.

15. Sanson RL. The epidemiology of foot-and-mouth disease: Implications for New Zealand. New Zealand Veterinary Journal, 1994; 42:41-53.

16. Farez S, Morley RS. Potential animal health hazards of pork and pork products. OIE Scientific and Technical Review, 1997; 16:65-78.

17. DEFRA. Risk assessment report, March 2003. Available at: http://www.defra.gov.uk/animalh/illegali/pdf/ch3module11.pdf.

18. Christensen BB, Rosenquist H, Sommer HM, Nielsen NL, Fagt S, Andersen NL, Nørrung B. A model of hygiene practices and consumption patterns in the consumer phase. Risk Analysis, 2005; 26:49-60.

19. Blackwell JH, Nolan EJ, Rickansrud DA. Total caloric input of a thermal process as an index of lethality for foot-andmouth disease virus. Journal of Food Science, 1998; 53:185190.

20. Pagliaro AF, Masana MO, Sanjurjo ED, Fondevila NA, Rodriguez HR. Foot-and-mouth disease virus inactivation in miniburgers by a continuous dry-moist heat cooking system. Journal of Food Protection, 1996; 59:181-184. 